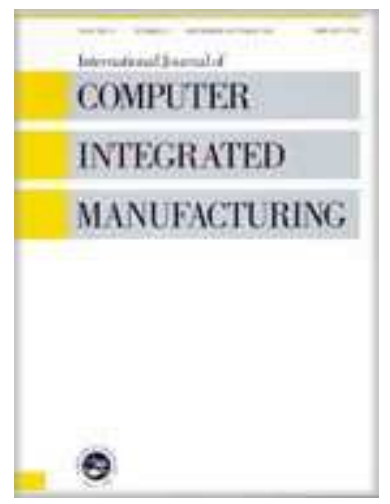

\title{
(DET2009) Modelling Dynamic Bottlenecks in Production Networks
}

\begin{tabular}{|c|c|}
\hline Journal: & International Journal of Computer Integrated Manufacturing \\
\hline Manuscript ID: & TCIM-2010-IJCIM-0016.R1 \\
\hline Manuscript Type: & Special Issue Paper \\
\hline $\begin{array}{l}\text { Date Submitted by the } \\
\text { Author: }\end{array}$ & 21-Jun-2010 \\
\hline Complete List of Authors: & $\begin{array}{l}\text { Scholz-Reiter, Bernd; Bremen University, Bremen Institute of } \\
\text { Industrial Technology and Applied Work Science (BIBA) at the } \\
\text { University of Bremen } \\
\text { Windt, Katja; Jacobs University, School of Engineering and Science } \\
\text { Liu, Huaxin; Bremen University, Bremen Institute of Industrial } \\
\text { Technology and Applied Work Science (BIBA) at the University of } \\
\text { Bremen }\end{array}$ \\
\hline Keywords: & $\begin{array}{l}\text { MODELLING, PRODUCTION MANAGEMENT, PRODUCTION CONTROL, } \\
\text { PRODUCTION FLOW ANALYSIS }\end{array}$ \\
\hline Keywords (user): & \\
\hline
\end{tabular}

\section{S ScholarONE \\ Manuscript Central}




\section{Revision Report}

Journal Title: International Journal of Computer Integrated Manufacturing Manuscript Reference: TCIM-2010-IJCIM-0016

Manuscript Title: Modelling Dynamic Bottlenecks in Production Networks

Authors: Bernd Scholz-Reiter, Katja Windt , Huaxin Liu

Data of this Revision: June 21, 2010

Firstly, I would like to take this opportunity to thank the editor and the two reviewers for their valuable comments and constructive suggestions that helped me improve the quality of this paper. My responses to the comments of reviewers are summarized in the following tables. All the modifications that have been made to the revision are highlighted in RED in the revised manuscript.

\section{Responses from the authors to Reviewer 1:}

\begin{tabular}{|c|c|c|}
\hline No. & Comments & Responses \\
\hline 1 & $\begin{array}{l}\text { There seems to be a lack of more recent publications. Please } \\
\text { consider including more recent wroks. }\end{array}$ & More recent works are mentioned in section 1 . \\
\hline 2 & $\begin{array}{l}\text { It is not mentioned in the paper about the impact of workers in } \\
\text { the problem solving. Is only hardware to be considered, or human } \\
\text { factors are also part of it? Please clarify. }\end{array}$ & $\begin{array}{l}\text { The impact of workers in the problem solving is } \\
\text { highlighted in the beginning of section } 4 \text {. } \\
\text { Afterwards, the impact of workers, as another } \\
\text { key role in solving problem, had been pointed } \\
\text { out in section } 4.3 \text { and } 5 \text {. }\end{array}$ \\
\hline
\end{tabular}


Responses from the authors to Reviewer 2:

\begin{tabular}{|c|c|c|}
\hline No. & Comments & Responses \\
\hline 1 & $\begin{array}{l}\text { In section 1"introduction", it is not enough to just give an } \\
\text { overview on the concept of and static methods for BOS or BOLA. } \\
\text { The author should put some efforts on the analysis of the } \\
\text { current research on dynamic bottleneck, especially the research } \\
\text { status for all the technologies used in dynamic bottleneck } \\
\text { analysis in the paper. }\end{array}$ & $\begin{array}{l}\text { An analysis of the current research on dynamic } \\
\text { bottleneck and the status for technologies used } \\
\text { in the paper are overviewed in section } 1 .\end{array}$ \\
\hline 2 & $\begin{array}{l}\text { The main contribution of the paper is to develop the definition } \\
\text { and measurement for dynamic bottleneck. So, it is important to } \\
\text { give a comparison between the static bottleneck and dynamic } \\
\text { bottleneck according to the definition and measurement methods. } \\
\text { It is better to use a table to show the differences in the } \\
\text { beginning of section } 2 \text {. }\end{array}$ & $\begin{array}{l}\text { An example of comparing the static and dynamic } \\
\text { bottlenecks is given in order to show their } \\
\text { difference in section } 3.2 \text {. }\end{array}$ \\
\hline 3 & $\begin{array}{l}\text { In the last paragraph of section } 3.2 \text {, The author stated that } \\
\text { "Most interestingly, the dynamic bottlenecks' shifting is in a } \\
\text { total chaotic state and might not be explained using fundamental } \\
\text { knowledge obtained from investigations on relative steady } \\
\text { processes." Can the author give the reason? Why cannot be are } \\
\text { explained using fundamental knowledge? Furthermore, can the } \\
\text { author prove the methods proposed in the paper is right. At } \\
\text { least, the author should give the Confidence Interval of the } \\
\text { simulation result. }\end{array}$ & $\begin{array}{l}\text { A possible reason, why the chaotic state of } \\
\text { bottleneck shifting cannot be are explained } \\
\text { using fundamental knowledge, is given. } \\
\text { Furthermore, a literature is shortly mentioned } \\
\text { in order to demonstrate the effectiveness of the } \\
\text { proposed methods in the last paragraph of } \\
\text { section } 3.2 \text {. }\end{array}$ \\
\hline 4 & $\begin{array}{l}\text { In the first paragraph of section 4, the author said "the } \\
\text { manufacturing process data must be continuously obtained by } \\
\text { building interface (e.g.ASCII interface) between eMplant and } \\
\text { Production Planning and Control(PPC) systems." What does "ASCII } \\
\text { interface" means? By API or just TXT files or database? }\end{array}$ & $\begin{array}{l}\text { The meaning of ASCII is added in the first } \\
\text { paragraph of section } 4 \text {. Reviewer could find the } \\
\text { details of this interface in literatures. }\end{array}$ \\
\hline 5 & $\begin{array}{l}\text { In the beginning of section } 4 \text {, it is strongly suggested to give } \\
\text { the description about the scenario, such as the background, the } \\
\text { problem, and the application effect. }\end{array}$ & $\begin{array}{l}\text { In the beginning of section } 4 \text {, a brief } \\
\text { description about application background and } \\
\text { scope as well as a potential benefit is } \\
\text { described. }\end{array}$ \\
\hline
\end{tabular}




\title{
Modelling Dynamic Bottlenecks in Production Networks
}

\author{
Bernd Scholz-Reiter ${ }^{a}$, Katja Windt ${ }^{\mathrm{b}}$, Huaxin Liu ${ }^{\mathrm{c}}$ \\ ${ }^{a}$ Bremen Institute of Industrial Technology and Applied Work Science (BIBA) at the \\ University of Bremen, Bremen University, Bremen, Germany \\ ${ }^{\mathrm{b}}$ School of Engineering and Science, Jacobs University, Bremen, Germany \\ ${ }^{c}$ Bremen Institute of Industrial Technology and Applied Work Science (BIBA) at the \\ University of Bremen, Bremen University, Germany \\ ${ }^{a}$ Bremen Institute of Industrial Technology and Applied Work Science (BIBA) at the \\ University of Bremen, Hochschulring 20, 28359 Bremen, Germany (Phone: +49 \\ (0)421/ 218-5576; Fax: +49 (0)421/218-5640; E-Mail: bsr@biba.uni-bremen.de) \\ ${ }^{b}$ Jacobs University, Campus Ring 1, 28759 Bremen, Germany (Phone: +49 421 200- \\ 3478; Fax: +49 421 200-3103; E-mail: k.windt@jacobs-university.de) \\ ${ }^{\mathrm{c}}$ International Graduate School for Dynamics in Logistics (IGS), Hochschulring 20, \\ 28359 Bremen, Germany (Phone: +49(0)421-218-5514; Fax: +49(0)421-218-5640; E- \\ mail: liu@biba.uni-bremen.de.de)
}

\begin{abstract}
Bottlenecks, as the key ingredients for improving the performances of the production networks, have been profoundly studied. However, the major definitions of bottlenecks are derived in terms of the throughput and based on the Theory of Constraints (TOC). Moreover, before the specific measures can be applied on them, it is not straightforward to localise dynamic bottlenecks due to their complex dynamic characteristics. Distinguishing from the traditional view at the bottlenecks, this paper therefore develops a systematic and comprehensive definition of dynamic bottlenecks of the production networks based on both the TOC and the Bottleneck Oriented Logistic Analysis (BOLA). Afterwards, the defined dynamic bottlenecks are modelled by means of discrete simulation using practical data, aiming at visualizing them in the production network. By applying the Logistic Operating Curves (LOCs), the practical application of the proposed research and its procedures is discussed as well.
\end{abstract}

Keywords: dynamic bottlenecks; production networks; discrete simulation, TOC, BOLA, LOCs

\section{Introduction}

In the past decades, a considerable amount of literature has been published on bottlenecks. The generalizability of the researches on this issue follows the Theory of Constraints (TOC) presented by Goldratt (Goldratt, 1990). The approach developed from Optimized Production Technology (OPT) which is now more commonly known as the Drum-Buffer-Rope (DBR) approach. In Goldratt's view (Goldratt, 1993), the Goal of a manufacturing organization is to make money. To make much money as 
possible, manufacturing enterprises must strive to increase throughput while minimizing operating expense and inventory. Since the latter two cannot be reduced endlessly (approach to zero), the main avenue or objective of developing a manufacturing system is maximizing the throughput. Thus, Goldratt described the throughput limitation of a manufacturing system as bottleneck and attempted to maximize the system throughput by locating bottleneck (e.g. bottleneck machine) and utilizing it as much as possible.

Although Goldratt mentioned that there are also some competitive objectives (e.g. high due-date performance, short quoted throughput time etc.) might be thought instead of the high throughput, maximizing throughout is only taken into account in his research because the contributions of the competitive objectives to making money is intangibles and impossible to be accounted by the financial systems (Goldratt and Fox, 1986). However, in order to survive in the globalised market, nowadays's manufacturing enterprises have to distinguish themselves from their competitors not only by producing quality products at high throughput, but also especially with a superior logistic performance (e.g. high delivery reliability and short delivery time). It is thus far from enough to describe the bottleneck of the manufacturing system only in terms of the throughput. Accordingly, there is a great necessity to identify bottlenecks from a logistics perspective and to implement specific measures on them, as so to improve logistic performance and reduce logistic cost.

Therefore, the Bottleneck Oriented Logistic Analysis (BOLA), as an ongoing control method designed for logistically evaluating and improving production process, is developed by Wiendahl (1993, 1995 and 1998) and Nyhuis (1999). Based on the BOLA, Windt concentrated on definitions of different bottlenecks types and developed a Bottlenecks Oriented Subcontracting (BOS) method for production 
networks (Windt, 2001). In the BOLA, based on the systematic analysis of manufacturing process data, the logistic objective-oriented bottleneck workstations, which including throughput time, schedule adherence, utilization and Work in Process oriented bottleneck workstation, can be localised in the observation period. By using the Logistic Operating Curves (LOCs) (Nyhuis, 1999), the logistic potential of the bottleneck workstation can be quantified through the logistic positioning (Nyhuis, 2007). The appropriate measures can then be applied to the localised bottleneck workstation so as to develop its logistic potential. In this way, the performance of the manufacturing system can be enhanced by developing the existing logistic potential of the bottleneck workstation. For instance, in order to achieve the short delivery time, the throughput time oriented bottleneck workstation is localised, and the target throughput time of this workstation is derived at first. The measures (e.g. temporarily increasing capacity) can afterwards be applied to the bottleneck workstation until its target throughput time is reached.

However, the BOLA and BOS as well as the OPT also suffers a number of limitations. Among them, the common and prominent one is that the investigated bottlenecks are derived based on the statistical analysis of manufacturing process data, thus they are called as static bottlenecks for a certain observation period. Due to the sequence of random events (e.g. equipment failures, variations in demand patterns, unsatisfied raw material delivery etc.) as well as the gradual change of the manufacturing systems, the bottlenecks are not static but dynamic, which stay not still but rather "shift" or "wander" in both time and space, so-called bottlenecks shifting or wandering (Stephen, 1995 and Zäpfel, 1998). Consequently, implementing the measures on the static bottlenecks does not always yield ideal results. The most likely causes of this problem are: on one hand, the measures are sometimes applied to the 
mislocated bottlenecks in the whole observation period; on the other hand, implementing the measures on bottlenecks leads to bottlenecks shifting, which again causes that the measures are applied to the mislocated bottlenecks.

Since consideration of dynamic bottlenecks plays a deceive role at all the levels of decision-makings in production practice (e.g. production planning, production scheduling and production control) and in decision-making for strategic investments (e.g. new facility purchases etc.), there has been an increasing amount of literature on identifying the dynamic bottleneck (for example, (Pollett, 2000), (Chiang and Kuo, 2000), (Roser and Nakano 2003), (Delp et al., 2003), ( Wang et al.,2005), (Yan et al., 2006 and 2009)). Nonetheless, these researches are barley focused on detecting the dynamic bottleneck which is defined in terms of the throughput under the philosophy of the TOC, the other competitive objectives oriented dynamic bottlenecks have not been investigated thoroughly.

In order to cope with the discussed limitations of previous studies, this paper develops a systematic and comprehensive definition of dynamic bottlenecks in the production networks with regards to multiple objectives (i.e. throughput time, relative lateness, schedule reliability, WIP, utilisation loss, throughput) and production resources (i.e. workstation and production segment). Via modelling the predefined dynamic bottlenecks based on a practical case, they are concretely visualized and their complex dynamic characteristics as well as clear differences from static bottlenecks are demonstrated. Aiming at supporting improvement of existing production processes with minimal efforts, a practical application of this study and its recommend procedures are developed to present the specific causes of problems in the form of cause-and-effect relationships. Distinguishing from the existing approaches, the proposed method expands the application range from one-time achievement of a 
single objective to simultaneous accomplishment of multiple objectives for networked manufacturing enterprises.

The rest of this paper is organized as follows. Section 2 systematically defines the dynamic bottlenecks of production networks. After introducing a discrete simulation model established by using practical data from a German hanger manufacturer, the dynamic bottlenecks are visualized and their complex dynamics are presented in section 3. Section 4 discusses the main concept and proposed procedures for practical application of configuring and modelling the dynamic bottlenecks. At last, major advantages and disadvantages of the proposed research are summarized in section 5 .

\section{Dynamic bottlenecks in production networks}

From the logistic point of view, manufacturing enterprises, especially in the Make-ToOrder (MTO) environment (Kuroda and Takeda 1998), strive to accomplish the different internal logistic objectives (figure 1) in the manufacturing area, so as to achieve high logistic performance or reduce logistic cost. As noted already, the dynamic bottlenecks should be thus identified with respect to not only the high throughput, but also the competitive objectives (i.e. internal logistic objectives). Since output lateness can be indicated by both relative lateness and schedule reliability, we only focus on the internal logistic objectives, except for the output lateness. Therefore, the dynamic bottlenecks in this paper are respectively defined regarding to throughput time, relative lateness, schedule reliability, WIP and utilisation as well as the system throughput (i.e. output rate).

(Insert Figure 1 about here)

Furthermore, when the production network, in which various products must be processed on multiple workstations located in different production segments, is 
considered as a whole, any components or subsystems of the production network can become its bottlenecks. To improve production network performance, the specific measures must be thus applied to both bottleneck workstations and bottleneck production segments. Consequently, the dynamic bottlenecks can be configured not only in terms of the different objectives but also regarding production segments and workstations. Since the bottleneck production segment, as the whole of the individual workstations, must be derived from the definition of bottleneck workstations, we will firstly define the bottleneck workstations as follows.

\subsection{Bottleneck workstations}

\subsubsection{Throughput time (TTP) bottleneck}

In order to obtain short delivery time, manufacturing enterprises usually strive to reduce the throughput times of workstations. As shown in figure 2, the sum of all the order throughput times corresponds to the sum of the operation throughput times of each workstation (equation (1)),

$\sum_{\mathrm{k}=1}^{\mathrm{m}} \mathrm{TTP}_{\text {order, }}=\sum_{\mathrm{j}=1}^{\mathrm{w}} \sum_{\mathrm{i}=1}^{\mathrm{n}} \mathrm{TTP}_{\mathrm{i}}$

(Nyhuis, 2003) (1)

Where

TTPorder,k : Order throughput time for the order k [hrs]

$\mathrm{TTP}_{\mathrm{i}}$ : Throughput time per operation [hrs]

$\mathrm{m}$ : Number of orders [-]

$\mathrm{j}$ : Number of workstation [-]

$\mathrm{n}$ : Number of accomplished operations per workstation [-]

$\mathrm{w}:$ Number of workstations [-]

(Insert Figure 2 about here)

The relative proportion of throughput time $\left(\mathrm{TTP}_{\mathrm{rp}}\right)$ thus directly describes the degree to which the individual workstations contribute to the order throughput time and can be calculated as: 
$\mathrm{TTP}_{\text {rp }}=\frac{\sum_{\mathrm{i}=1}^{\mathrm{n}} \mathrm{TTP}_{\mathrm{i}}}{\sum_{\mathrm{j}=1}^{\mathrm{w}} \sum_{\mathrm{i}=1}^{\mathrm{n}} \mathrm{TTP}_{\mathrm{i}}} \cdot 100$

Adapted from (Windt, 2001) (2)

Where

TTP $_{\text {rp }}$ : Relative proportion of throughput time [\%]

TTP $_{\mathrm{i}}$ : Throughput time per operation [hrs]

$\mathrm{n}$ : Number of accomplished operations [-]

$\mathrm{w}:$ Number of workstations [-]

When this calculation is completed for each of the workstations they can be ranked according to which ones measures for reducing the throughput time should be primarily implemented on. Therefore, the throughput time bottleneck workstation (BNTTPws) can be described as the workstation $\mathrm{j}$ with the maximum $\mathrm{TTP}_{\mathrm{rp}}$ as following:

$\mathrm{BNTTP}_{\mathrm{ws}}=\left\{\mathrm{j} \mid \mathrm{TTP}_{\mathrm{rp}, \mathrm{j}}=\max \left(\mathrm{TTP}_{\mathrm{rp}, 1}, \mathrm{TTP}_{\mathrm{rp}, 2}, \ldots, \mathrm{TTP}_{\mathrm{rp}, \mathrm{w}}\right)\right\}$

\subsubsection{Relative lateness $(R L)$ bottleneck}

In the manufacturing area, the output schedule lateness of an operation can be caused by both input lateness and the relative lateness. The latter is the result of the difference between the actual throughput time and the target throughput time as shown in figure 3.

(Insert Figure 3 about here)

Therefore, the relative lateness can be used to identify whether the output schedule situation worsened or improved compared to the input situation. The sum of all the order relative lateness corresponds to the sum of the operation relative lateness of each workstation, as following described:

$\sum_{\mathrm{k}=1}^{\mathrm{m}} \mathrm{RL}$ order, $\mathrm{k}=\sum_{\mathrm{j}=1}^{\mathrm{w}} \sum_{\mathrm{i}=1}^{\mathrm{n}} \mathrm{R} \mathrm{L}_{\mathrm{i}}$

Where

$\mathrm{RL}$ order,k: Relative lateness for the order $\mathrm{k}$ [hrs]

$\mathrm{RL}_{\mathrm{i}}$ : Relative lateness per operation [hrs]

$m$ : Number of orders [-]

$\mathrm{j}$ : Number of workstation [-] 
$\mathrm{n}$ : Number of accomplished operations per workstation [-]

w : Number of workstations [-]

Consequently, the relative proportion of relative lateness $\left(R L_{r p}\right)$ describes the degree to which the individual workstations contribute to the order relative lateness and can be defined as:

$R L_{r p}=\frac{\sum_{i=1}^{n}\left|R L_{i}\right|}{\sum_{j=1}^{W} \sum_{i=1}^{n}\left|R L_{i}\right|} \cdot 100$

(Windt, 2001) (5)

Where

$\mathrm{RL}_{\mathrm{rp}}$ : Relative proportion of relative lateness [\%]

$\mathrm{RL}_{\mathrm{i}}$ : Relative lateness per operation [hrs]

$\mathrm{n}$ : Number of accomplished operations [-]

$\mathrm{w}$ : Number of workstations [-]

When the relative proportion of relative lateness for each workstation is available, all the workstations can be ranked according to the $\mathrm{RL}_{\mathrm{rp}}$ values. And the relative lateness bottleneck workstation (BNRLws) can be described as the workstation $\mathrm{j}$ with the maximum $\mathrm{RL}_{\mathrm{rp}}$ as following:

$\mathrm{BNRL}_{w s}=\left\{\mathrm{j} \mid \mathrm{RL}_{\mathrm{rp}, \mathrm{j}}=\max \left(\mathrm{RL}_{\mathrm{rp}, 1}, \mathrm{RL}_{\mathrm{rp}, 2}, \ldots, \mathrm{RL}_{\mathrm{rp}, \mathrm{w}}\right)\right\}$

\subsubsection{Schedule reliability (ReS) bottleneck}

In the production area, high levels of schedule reliability of the workstations are a prerequisite for accomplishing high level of delivery reliability (Lödding et al, 2002). Under the conditions that throughput time is normally distributed and orders are completed follow the dispatching sequence rule First-In-First-Out (FIFO), the schedule reliability of the workstation can be calculated like the probabilities of a normal distributed random variable $\operatorname{WIP}(\mathrm{t})(\mathrm{Yu}, 2001)$. The calculation is based on the distribution function $\phi(u)$ for the standard deviation (Papula, 1994) and is written as: 
$\operatorname{ReS}(\mathrm{WIP}(\mathrm{t}))=\phi\left(\frac{\mathrm{UB}-\mathrm{TIO}_{\mathrm{m}}(\mathrm{WIP}(\mathrm{t}))}{\mathrm{TIO}_{\mathrm{s}}(\mathrm{t})}\right)-\phi\left(\frac{\mathrm{LB}-\mathrm{TIO}_{\mathrm{m}}(\mathrm{WIP}(\mathrm{t}))}{\mathrm{TIO}_{\mathrm{s}}(\mathrm{t})}\right)$ Adapted from $(\mathrm{Yu}, 2001)$ (7)

Where

$\operatorname{Re} S$ : Schedule reliability [\%]

WIP( $\mathrm{t})$ : WIP level [hrs]

$\mathrm{LB}=\mathrm{TIO}_{\mathrm{p}}-\mathrm{TTZ}[\mathrm{SCD}]$

$\mathrm{UB}=\mathrm{TIO}_{\mathrm{p}}+\mathrm{TTZ}[\mathrm{SCD}]$

TTZ : Schedule tolerance [SCD]

LB : Lower bound [SCD]

UB: Upper bound [SCD]

$\mathrm{TIO}_{\mathrm{m}}(\mathrm{WIP}(\mathrm{t}))$ : Mean inter-operation time [SCD]

$\mathrm{TIO}_{\mathrm{s}}(\mathrm{t})$ : Standard deviation of inter-operation time [SCD]

The schedule reliability bottleneck workstation (BNReSws) can therefore be determined as the workstation $\mathrm{j}$ with the minimum schedule reliability as following:

$\mathrm{BNReS}_{\mathrm{ws}}=\left\{\mathrm{j} \mid \operatorname{Re} \mathrm{S}_{\mathrm{j}}=\min \left(\operatorname{ReS}_{1}, \operatorname{ReS}_{2}, \ldots, \operatorname{ReS}_{\mathrm{w}}\right)\right\}$

\subsubsection{Work in Process (WIP) Bottleneck}

Generally speaking, the WIP (written in equation (9)) is an independent objective, and reducing the WIP serves only as a means of obtaining short throughput time from a logistics perspective. However, if the goal is to minimize tied-up capital or release available floor space, the WIP can be treated separately from the throughput time from the economic point of view. To describe the tied-up capital, it is necessary to compile the order value of each operation and include it in the calculation. On the other hand, if making floor space is mainly focused, the supplementary information about the actual space required each specific operation is needed.

$\mathrm{WIP}(\mathrm{t})=\operatorname{IWIP}-\operatorname{IN}(\mathrm{t})-\mathrm{OUT}(\mathrm{t})$

Where

WIP(t) : WIP level of workstation [hrs]

IWIP : Initial WIP level

$\mathrm{IN}(\mathrm{t})$ : Input (cumulative work content of the incoming operations) [hrs]

OUT(t) : Output (cumulative work content of the outgoing operations) [hrs]

So, the WIP bottleneck workstation ( BNWIPws) can be determined as the workstation j with the maximum WIP : 
$\mathrm{BNWIP}_{\mathrm{ws}}=\left\{\mathrm{j} \mid \mathrm{WIP}_{\mathrm{j}}=\max \left(\mathrm{WIP}_{1}, \mathrm{WIP}_{2}, \ldots, \mathrm{WIP}_{\mathrm{w}}\right)\right\}$

\subsubsection{Utilization loss (UL) bottleneck}

The utilization of the workstation is generally determined by comparing of its mean output rate and maximum output rate (Nyhuis and Wiendahl, 2008). However, the generally defined utilization is limitedly measured and adapted over a long term period (e.g. days or weeks). Apparently, in order to model the utilization related bottleneck over a short term period, the general definition cannot be employed.

In a high-wage country such as Germany the available capacity mainly depends on not equipment but operator capacity, the latter can be used to express the utilization by introducing the relative Work in Process ( WIPrel $)$, which reflects the scope of the available operator capacity and can be measured comparably quickly to changes in the load situation. According to the normalized Logistic Operating Curves, there will not be significant utilization loss under the condition of WIP $\mathrm{Pel}>250 \%$ (Nyhuis and Wiendahl, 2008). The utilization loss bottleneck workstation (BNUL ws) can be therefore determined as the workstation $\mathrm{j}$ with the maximum utilisation loss (UL):

$$
\mathrm{BNULws}=\left\{\mathrm{j} \mid \mathrm{UL}_{\mathrm{j}}=\max \left(\mathrm{UL}_{1}, \mathrm{UL}_{2}, \ldots, \mathrm{UL}_{\mathrm{w}}\right)\right\}
$$

In equation (11), the utilisation loss of each workstation is greater than zero and can be derived based on the $\mathrm{WIP}_{\text {rel }}(\mathrm{t})$ using equation (12):

$$
\mathrm{UL}(\mathrm{t})=2.5-\mathrm{WIP}_{\mathrm{rel}}(\mathrm{t})
$$

The WIPrel $(t)$ level of each workstation can be calculated by applying equation (13)(14) according to Nyhuis and Wiendahl (Nyhuis and Wiendahl, 2008):

$$
\mathrm{WIP}_{\text {rel }}(\mathrm{t})=\frac{\mathrm{WIP}_{\mathrm{m}}(\mathrm{t})}{\mathrm{WIPI}_{\min }(\mathrm{t})}
$$

Where

$\mathrm{WIP}_{\text {rel }}(\mathrm{t})$ : Relative WIP level [\%] 
$\mathrm{WIP}_{\mathrm{m}}(\mathrm{t})$ : Mean WIP level [hrs]

WIPI $_{\text {min }}$ : Ideal minimum WIP level [hrs]

$\mathrm{WIPI}_{\min }(\mathrm{t})=\frac{\sum_{\mathrm{i}=1}^{\mathrm{n}}\left(\mathrm{WC}_{\mathrm{i}} \cdot \mathrm{WC}_{\mathrm{i}}\right)}{\sum_{\mathrm{i}=1}^{\mathrm{n}} \mathrm{WC}_{\mathrm{i}}}$

Where

WIPI $_{\text {min }}$ : Ideal minimum WIP level [hrs]

$\mathrm{WC}_{\mathrm{i}}$ : Work content of operation per lot [hrs]

$\mathrm{n}$ : Number of accomplished operations [-]

\subsubsection{Throughput (TT) bottleneck}

Apart from the internal logistic objectives, manufacturing enterprises generally strive to maximize the system throughput (i.e. output rate) so as to make much money as possible, as we disused in Section 1. Thus, it is necessary to identify the capacity constraint, named as throughput bottleneck. Distinguishing from the above defined bottlenecks, identifying the throughput bottleneck is not straightforward and a considerable amount of literature has thus been published on this issue.

The previous studies can be divided into four main categories. Among them, measuring average waiting time belongs to the first category. When measuring the average waiting time, the machine with the longest average waiting time is considered to be the throughput bottleneck (see e.g., Pollett, 2000). Regarding to the Little's law, measurement of average queue length is also within this category. This method is suitable for analyzing production networks with unlimited intermedial buffers. For systems containing only limited buffers and systems without buffers, it is not a suitable choice. In the second category, the throughput bottleneck is detected by measuring average utilization (workload) and the machine with the largest busy/idle ratio is considered as the throughput (see e.g., Law and Kelton, 1991). As more than one machine may have a similar workload, the difference between the utilizations of the machines may be very small. Although this method is easy to automate, it may 
result in multiple bottlenecks. On the other hand, it is also difficult to identify the dynamic bottlenecks as discussed in last section. Another way to identify the throughput bottleneck is to find the machine whose throughput mostly affects the overall system throughput, i.e. measuring the sensitivity (see e.g., Chiang and Kuo, 2000). The sensitivity of the system performance to the perturbation of machine parameters is used as the measurement. Except for the above-described methods, measuring the active duration was developed by Roser and Nakano (see e.g., Roser and Nakano, 2003). When measuring the active duration, the machine with the longest average active period is recognized as the bottleneck. The active state of machine is different from traditional busy concept. All activities towards improving the system throughput including repair and service states are active states. With simulation results in a production line, they argued that the proposed method can more accurately detect the dynamic bottleneck based on the sensitivity definition.

These throughput bottleneck identification methods have also some disadvantages, neither too complex for the practical applications (measuring the sensitivity and active duration) or the difficulty in identifying the dynamic bottleneck (e.g. measuring the average utilization). By contrast, the method of measuring queue length is easy to implement and can effectively identify the dynamic bottleneck if the system contains unlimited size buffers. This method is thus applied to our study, and the workstation with the longest queue (i.e. the highest WIP level) is defined as the throughput bottleneck as we discussed in Section 2.1.4.

\subsection{Bottleneck production segments}

Apart from the bottleneck workstations, in the production network the bottleneck production segments, which consist of several workstations, can also be determined on the basis of the definition of the bottleneck workstations. Because the modelling of 
the dynamic bottlenecks is based on a practical case, in this paper we only investigate the production network in which the individual production segments consist of parallel workstations.

In the case that each production segment of the production network consists of several parallel workstations, in which incoming orders are processed following the uniform distribution, (i.e. the parallel workstations in a production segment have the same possibility to produce incoming orders), the parallel workstations are less dependent on each other and make the equal contribution to the bottlenecking degree of the production segment. Therefore, the bottleneck indicators of production segments can be determined by the mean values of the bottleneck workstations' indicators by using equation (15)-(19), in which the variable $\mathrm{w}_{\mathrm{ps}}$ represents the number of workstation in a production segment.
$\mathrm{TTP}_{\mathrm{rp}, \mathrm{ps}}=\frac{\sum_{\mathrm{j}=1}^{\mathrm{w}_{\mathrm{ps}}} \mathrm{TTP}_{\mathrm{rp}, \mathrm{j}}}{\mathrm{W}_{\mathrm{ps}}}$
$R L_{r p, p s}=\frac{\sum_{j=1}^{w_{p s}} R L_{r p, j}}{W_{p s}}$
$\operatorname{ReS}_{\mathrm{ps}}=\frac{\sum_{\mathrm{j}=1}^{\mathrm{w}_{\mathrm{ps}}} \operatorname{ReS}_{\mathrm{j}}}{\mathrm{W}_{\mathrm{ps}}}$
$\mathrm{WIP}_{\mathrm{ps}}=\mathrm{TT}_{\mathrm{ps}}=\frac{\sum_{\mathrm{j}=1}^{\mathrm{w}_{\mathrm{ps}}} \mathrm{WIP}_{\mathrm{j}}}{\mathrm{Wps}_{\mathrm{ps}}}$
$\mathrm{UL}_{\mathrm{ps}}=\frac{\sum_{\mathrm{j}=1}^{\mathrm{W}_{\mathrm{ps}}} \mathrm{UL}_{\mathrm{j}}}{\mathrm{W}_{\mathrm{ps}}}$

After the bottleneck indicators of individual production segments are derived, the bottleneck production segments can be respectively determined as the production segment $\mathrm{i}$ as following:

$$
\begin{aligned}
& \mathrm{BNTTP}_{\mathrm{ps}}=\left\{\mathrm{i} \mid \mathrm{TTP}_{\mathrm{rp}, \mathrm{ps}, \mathrm{i}}=\max \left(\mathrm{TTP}_{\mathrm{rp}, \mathrm{ps}, 1}, \mathrm{TTP}_{\mathrm{rp}, \mathrm{ps}, 2}, \ldots, \mathrm{TTP}_{\mathrm{rp}, \mathrm{ps}, \mathrm{n}}\right)\right\} \\
& \mathrm{BNRL}_{\mathrm{ps}}=\left\{\mathrm{i} \mid \mathrm{R} L_{\mathrm{rp}, \mathrm{ps}, \mathrm{i}}=\max \left(\mathrm{RL}_{\mathrm{rp}, \mathrm{ps}, 1}, \mathrm{R} L_{\mathrm{rp}, \mathrm{ps}, 2}, \ldots, \mathrm{R} \mathrm{L}_{\mathrm{rp}, \mathrm{ps}, \mathrm{n}}\right)\right\} \\
& \mathrm{BNReS}_{\mathrm{ps}}=\left\{\mathrm{i} \mid \operatorname{Re} S_{\mathrm{ps}, \mathrm{i}}=\min \left(\operatorname{ReS}_{\mathrm{ps}, 1}, \operatorname{ReS}_{\mathrm{ps}, 2}, \ldots, \operatorname{ReS}_{\mathrm{ps}, \mathrm{n}}\right)\right\} \\
& \mathrm{BNWIP}_{\mathrm{ps}}=\mathrm{BNTT}_{\mathrm{ps}}=\left\{\mathrm{i} \mid \mathrm{WIP}_{\mathrm{ps}, \mathrm{i}}=\max \left(\mathrm{WIP}_{\mathrm{ps}, 1}, \mathrm{WIP}_{\mathrm{ps}, 2}, \ldots, \mathrm{WIP}_{\mathrm{ps}, \mathrm{n}}\right)\right\} \\
& \mathrm{BNUL}_{\mathrm{ps}}=\left\{\mathrm{i} \mid \mathrm{UL}_{\mathrm{ps}, \mathrm{i}}=\max \left(\mathrm{UL}_{\mathrm{ps}, 1}, \mathrm{UL}_{\mathrm{ps}, 2}, \ldots, \mathrm{UL}_{\mathrm{ps}, \mathrm{n}}\right)\right\}
\end{aligned}
$$




\section{Modelling dynamic bottlenecks}

\subsection{Simulation Model introduction}

In order to model the dynamic bottlenecks, a discrete event simulation model has been developed in eMplant 8.2 by using practical data which is exported from a dynamic capacity planning and control program (FAST/Pro) and mainly includes:

1) Production order data

- order number

- lot size

- start, begin and end of target date

- actual start, begin and end date

- routing plan

2) Operation data

- workstation number

- operation number

- operation sequence number

- work contents

- start, begin and end of target date

- actual start, begin and end date

- processing time and setup time

3) Workstation data

- production segment number

- workstation number

- shift calendar

The simulation model describes a partial production network of a German hanger manufacturer. The production network consists of four production segments which are located at different places and represent different processing steps including manual turning (PS78), CNC turning (PS79), drilling (PS77) and CNC center (PS81). Each production segment works in the given shift calendar and consists of several parallel workstations (Table 1).

(Insert Table 1 about here)

The four production segments are connected via the complex material flows including not only top-down flow but also reverse and re-entry flow (figure 4), in 
which the numbers represent the amount of the order flows during a two years period (2003 and 2004).

(Insert Figure 4 about here)

Moreover, the hanger manufacturer is a typical MTO enterprise and produces a wide range of customer-related products. The incoming production orders have the diverse characteristics in terms of quantities, lot sizes, numbers of operations and work content of operations as shown in figure 5.

(Insert Figure 5 about here)

The production network is under Dynamic Capacity Planning and Control (Wiendahl, 1995). Each production segment as a basic capacity pot is placed a certain amount of load regarding its capacity limit. In shop floor simulation, the incoming orders are distributed among individual workstations following the uniform distribution function within a production segment, and processed following the FIFO rule at each workstation. Besides, regarding the impacts of the schedule tolerance and the mean value of due date distribution on schedule reliability (Nyhuis, 2006), the schedule tolerance and the mean value of due date distribution are respectively set at +/- 0.7 SCD and 0.8 SCD, the both of which are derived based on the statistical analysis of the average planned inter-operation times.

\subsection{Visualizing Dynamic bottlenecks}

Figure 6 to 10 present that the dynamic bottlenecks shift in time (X axis) and space ( $\mathrm{Y}$ axis) in a randomly selected observation period (from 01.04.2003 until 30.06.2003). The horizontal length of lines present the time duration of the production segments and workstations being bottlenecks. The vertical changes of lines show that the bottlenecks jump from one workstation and production segment to another.

(Insert Figure 6, 7, 8, 9 and10 about here) 
From the figures above we can see that the dynamic bottlenecks dramatically shift in the production network, especially the throughput (or WIP) bottlenecks (Figure 9). For instance, as shown in Figure 6 workstation 37703 was the throughput time bottleneck until 10th of June, and then workstation 37701, 37703 and 37704 turned into the bottleneck alternately, and production segment 77 was always the throughput time bottleneck in the entire observation period.

In contrast, the static throughput time bottlenecks, both workstation and production segment, are derived by using equation (2), (3), (15) and (20) and based on statistical simulation results collected in the observation period (from 01.04.2003 until 30.06.2003). As can be seen from Table 2, the workstation 37701 and production segment 77 , respectively, have the maximum relative proportion of throughput time and thus were identified as the static bottlenecks. By comparing the locations of static and dynamic throughput time bottlenecks, a clear difference between the static and dynamic bottlenecks can be observed. It indicates the significance of investigating and modelling the dynamic bottlenecks as well.

(Insert Table 2 about here)

Moreover, the different objectives oriented bottlenecks might be overlapped. For instance, production segment 77 was throughput time, relative lateness, throughput and WIP bottlenecks from 10th to 30th of June (Figure 6, 7 and 9). Most interestingly, the dynamic bottlenecks' shifting is in a total chaotic state and might not be explained using fundamental knowledge obtained from investigations on relative steady processes. For example, it is well known that for both production segment and workstation the high WIP level inevitably results in the long throughput time in a long term observation period. Hence, the throughput time bottlenecks are supposed to be consistent with the WIP bottlenecks, and the both bottlenecks should synchronously 
shift to the same production resources. Nevertheless, the controversial phenomenon is demonstrated by comparing the locations of the throughput time and WIP bottlenecks as shown in Figure 6 and 9. In the observation period, the throughput time bottleneck production segment is production segment 77 . In contrast, the WIP bottleneck production segment jumps among the four production segments until about end of May and then locates at the production segment 77 . As to the bottleneck workstation, workstation 37703 is the throughput time bottleneck until 10th of June, but the WIP bottleneck workstation jumps among all the workstations in the same observation period.

This phenomenon might result from complex dynamics of dynamic bottlenecks, which also could lead to difficulties in practical applications of proposed research. To overcome this problem, effective fault detection and isolation approaches could be developed. For example, the complex dynamics of dynamic bottleneck was first demonstrated experimentally by Scholz-Reiter (Scholz-Reiter et. al, 2009). In their study, a fault detection and isolation approach was developed with regards to the throughput time bottleneck workstation. To verify its effectiveness, the identified dynamic bottleneck is considered in a release control process. The main idea is that aiming at decreasing the throughput time of whole production system, the developed release control mechanism offers the customer orders, which are not about to be processed by the bottleneck, the priority to release at first, i.e. the throughput bottleneck workstation always refuse to produce more until another workstation becomes the bottleneck. The simulation results indicates that the release decisions made based on the identified dynamic bottleneck, combing with the application of the fault detection and isolation approach, are able to reduce the throughput time of production system. 


\section{Application}

The proposed research is mainly developed to support the improvement of existing production processes by localising and presenting the specific causes of problems in the form of cause-and-effect relationships. Primary application objects could include middle or large scale production networks, which conduct manufacturing activities based on customer specifications and there are frequent changes to the product design. Due to the complexity of these production networks, it is not convenient to modify the existing manufacturing processes and approaches or redesign a whole set of new ones. Nonetheless, constant market pressures push them to do so in order to continuously improve logistic performance and/or reduce logistic cost. It thus becomes a crucial issue that achieving the goal with minimal efforts, and the proposed application of this study comes forward. Because of the diversity of production networks caused by diverse products, different marketing strategies and changing customer demands, software of Production Planning and Control (PPC) systems etc., the proposed application should be adopted according to different circumstances in practice. In this paper, we only focus on a fundamental application of configuring and modelling dynamic bottlenecks with regards to the investigated hanger manufacturer.

In order to apply the proposed research to practice, the manufacturing process data must be continuously obtained by building interface between eMplant and PPC systems, e.g. the American Standard Code for Information Interchange (ASCII) interface, which, as a standard interface, is installed in most PPC systems and eMplant. Moreover, employees need to be well educated with regards to fundamental and systematic theories of production logistics and PPC as well as production processing designing, so as to assure an effective and efficient application. On this basis, the objectives-oriented dynamic bottlenecks can be localised in real time, and 
their existing logistic potentials for improvement can be derived with the integration of the synchronous logistic positioning, as shown in figure 11. Afterwards, the appropriate measures can be determined and applied to the determined dynamic bottlenecks so that the production network performance can be improved by developing the logistic potentials of the bottlenecks. For the practical application, it is strongly recommended that the following specific steps are followed.

(Insert Figure 11 about here)

\subsection{Choosing bottlenecks}

First and foremost, the choice of bottlenecks has to be oriented on the concrete analysis of the enterprise's goals. Generally, an enterprise establishes not a single but multiple goals (i.e. short throughput time, low relative lateness, high schedule reliability, low WIP level, low unitisation loss and high output rate) according to actual situation. The bottlenecks (bottleneck workstations and bottleneck production segments) can be then chosen in terms of the focused objectives. Moreover, those objectives are always connected with each other and to some extent might contradict one another (Gutenberg, 1951). In the case that a bottleneck is identified as the bottleneck relevant to multi-objectives (i.e. overlapped bottleneck), it is necessary to rank the priority of each objective at first so that the prioritized objective-oriented measures can be determined.

For instance, an enterprise's main goal is to shorten throughput time; meanwhile because relative lateness is also needed to be reduced, the low relative lateness can be determined as its secondary goal. Therefore, the throughput time and relative lateness bottlenecks can be chosen. If both of them have the existing logistic potentials for improvement, the corresponding measures for shortening throughput time (e.g. shifting load location) and reducing relative lateness (e.g. remaining the 
WIP at the planned level) should be applied to the bottlenecks, respectively. In the case that the bottlenecks are overlapped as described in section 3.2, the measures only for shortening throughput time are supposed to be applied to the overlapped bottleneck production segment 77 .

For example, as noted already, the throughput bottleneck and WIP bottleneck are defined as the identical production resources (i.e. both workstations and work systems). When a manufacturer establishes the low WIP level and high output as the goals, aiming at, on one hand, making money as much as possible, on the other hand, saving the production costs (removing production waste) to increase the value of end products, both of the goals must be prioritized at first. The priority of the two goals directly determines the corresponding measures. If the high throughput is established as the principal goal, the measures for fully utilizing the bottleneck (e.g. remaining the buffer inventory of the bottleneck at a safety WIP level, like the Starvation Avoidance (Glassey, 1988)) should be employed. On the contrary, the WIP level of the bottleneck should be reduced as much as possible so as to reduce WIP of the whole production network, as long as the bottleneck resources not interrupt the material flow of the whole production network.

\subsection{Logistic positioning}

After choosing the bottlenecks relevant to the existing goals, the logistic positioning must be conducted on all of the bottlenecks before the specific measures can determined. In the logistic positioning, the target values for the logistic objectives are determined based on the current manufacturing situations. By using the LOCs (figure 12), it becomes clear whether or not the target values are consistent and achievable, or if it is necessary to develop additional logistic potential. For instance, if the actual throughput time level of the throughput time bottleneck workstation is higher than the 
target level, it implies that this bottleneck workstation has the potential for reducing throughput time, for example, by increasing its capacity or shifting load location. Otherwise, it is necessary to develop the new additional logistic potential (e.g. by facilitating overlapped manufacturing).

(Insert Figure 12 about here)

Apart from the logistic positing in terms of throughput time, relative lateness and schedule reliability, it is also necessary to independently conduct the logistic positioning regarding the utilisation cost and the WIP cost. Although this task cannot be immediately accomplished by using the Production Cost Operating Curve (PCOC), the both types of costs can be depicted by decomposing the total costs according to Jainczyk (1994), Großklaus (1996) and Kerner (2002). Because the total costs, as the function of output rate and WIP, are determined by the sum of production cost, processing cost, WIP cost and setup cost, each of the four type of costs can be descript as the function of WIP after the Output Rate Operating Curve (OROC) is derived. When the utilisation cost is approximated to the difference between the total costs and the WIP cost, the utilisation cost and the WIP cost can be independently depicted by the curves which can be further applied in the logistic positioning.

As noted already, the logistic positioning must be conducted on not only the bottleneck workstations but also the bottleneck production segments. However, the LOCs can only be applied in positioning the individual workstations, the quantifying the logistic potentials of the bottleneck production segments is hitherto impossible except for using the Manufacturing System Operating Curves (MSOC) (Schneider, 2004), which however can be applied in the logistic positioning only regarding to throughput time and output rate. 
Here it should be noted that the main concept of the proposed application, similar to the TOC's and the BOLA's, is to improve the performance of a whole (i.e. a production network) by improving the performance of its parts (i.e. bottlenecks). However, according to the dialectical whole and part (Bertell, 2003), the individual workstations can be considered as not only the parts of the production network but also the parts of the relevant production segment when we consider a production network and a production segment as a whole, respectively. Thus, the logistic potentials of a bottleneck production segment can be developed by implementing the measures on its bottleneck workstation until the desired performance of the production network is reached. Accordingly, it is only need to position the bottleneck workstation of bottleneck production segment, instead of directly positioning the bottleneck production segment. For example, production segment 77 was throughput time bottleneck from 31th of May to 10th of June (figure 6). Meanwhile, workstation 37701, which with the maximum TTP $_{\text {rр }}$ within production segment 77 and can be identified as the bottleneck workstation of bottleneck production segment 77 (figure 13). Therefore, the bottleneck workstation of bottleneck production segment (i.e. workstation 37701) as well as the bottleneck workstation of production network (i.e. workstation 37703 as shown in figure 6) is able to be positioned by using the LOCs. (Insert Figure 13 about here)

\subsection{Determining appropriate measures}

After choosing bottlenecks and logistic positioning, a wide range of possible measures can be developed and implemented on the bottleneck workstations of production network and the bottleneck workstations of bottleneck production segments. For instance, the possible measures to reduce throughput time might include: 1) production process designing (e.g. increasing capacity flexibility, implementing new 
manufacturing technologies etc.); 2) production planning (e.g. lot sizing, scheduling, loading and capacity planning etc.); 3) production control (e.g. increasing capacity, shifting workload, reducing or harmonizing work content, changing processing sequences etc.); 4) subcontracting (e.g. buying extra production capacity from partner companies ) (the details can be found in Windt (2001)) and so on and so forth.

Nevertheless, it should be noticed that not all of the possible measures but only few of them are preferable in the practice, and even the favour measures are not always preferred because of the changes of manufacturing situation and customers' demand. Therefore, in order to determine the appropriate measures, employees first require a systematic introduction into the fundamentals of production processing designing and PPC, preferably in conjunction with training, in which concrete examples from the company can be observed.

\section{Summary}

In this paper, we developed a systematic and comprehensive definition of the dynamic bottlenecks from a logistics perspective. By the means of modelling of the dynamic bottlenecks, not only the dynamic bottlenecks are visualized, but also their dynamic characteristics are demonstrated. Moreover, a practical guidance for utilizing the proposed research was also provided. In contrast to the BOLA, the proposed application concepts are able to not only overcome the main drawback of the application of the BOLA, but also expand the application range from one-time achievement of a single logistic objective to simultaneous trade-off multiple logistic objectives and from the individual production systems to the production networks.

However, the proposed application is a continuous improvement process, and it is thus necessary to permanently monitor the manufacturing by interfacing the established model with PPC systems. Furthermore, the employees need to be well 
educated with regards to the basics of production logistics and PPC so that they are always able to align the production process through choosing bottlenecks, logistic positioning, implementing appropriate measures and evaluating system performance according to the current manufacturing situation and market's demand. Future work will focus on realizing the proposed application within the context of production control. Aiming at trading-off multiple logistic objectives, a hybrid production control system, named as a Dynamic Bottleneck-oriented Manufacturing Control, will be developed on the basis of the modelling of the dynamic bottlenecks.

Acknowledgements: This work was supported by International Graduate School (IGS) for dynamics in logistics as well as Intelligent Production and Logistic Systems department at Bremen University. This paper has been presented in DET2009 conference held at the University of Hong Kong during 14-16 December 2009 and included in the conference proceeding published by Springer.

\section{References}

Bertell, O., 2003. Dance of the Dialectic: Steps in Marx's Method,Urbana, 36-51. Delp D., Si, J.Y. and Wang, H., 2003. A dynamic system regulation measure for increasing effective capacity: the X-factor theory, Advanced Semiconductor Manufacturing Conference and Workshop, 81-88.

Chiang S. Y. and Kuo, C. T., 2000.DT-bottlenecks in serial production lines: theory and application, IEEE Transctions on Robotics and Automation, 16,567-580.

Großklaus, A., 1996. Ablauforientierte Productionslogistik - eine modellbasierte Analyse, Dt. Univ. -Verlag, Gabler - Verlag, Wiesbaden.

Goldratt, E.M. and Fox, R.E, 1986. The Race, North River Press, Croton-on-Hudson, NY, 18-72.

Goldratt, E. M., 1990. Theory of Constraints, North River Press, Croton-on-Hudon, New York.

Goldratt, E.M., 1993. The Goal, Second Revised Edition, North River Press, Great Barrington, Mass.

Gutenberg, E., 1951. Grundlagen der Betriebswirtschaftslehre, Band 1: Die Produktion, Springer-Verlag, Berlin, Heidelberg, New York.

Glassey, C. R. and Resende, M. G. C., 1988. Closed-Loop Job Release Control for VLSI Circuit Manufacturing. IEEE Transactions on semiconductor manufacturing, 11, 36-46.

Jainczyk, M., 1994. Logistikorientierte Bewertung von Invesstitionsvorhaben im Productionsbereich, In: PSK-Fachtagung, gfmt, Munich,

Kuroda, M. and Takeda, K., 1998. General structure and characteristics of quick response production system", Comp. \& Ind. Eng., 395.

Kerner, A., 2002. Modellbasierte Baurteilung der Logistikleistung von Prozeßketten, Dissertation, Universität Hannover. 
Law A. M. and Kelton D. W., 1991.Simulation Modelling and Analysis, McGraw Hill.

Lödding, H. and Wiendahl, H.-P., 2002. Erfolgsfaktor Logistikqualität, Springer, Berlin, Heidelberg and New York, 34-46.

Lödding, H., 2005. Verfahren der Fertigungssteuerung, Springer-Verlag, Heidelberg, 19-39.

Nyhuis, P. and Wiendahl, H.-P., 1999. Logistische Kennlinien: Grundlagen, Werkzeuge und Anwendungen, 1nd Edition, Springer-Verlag, Berlin, Heidelberg, New York, 191-238.

Nyhuis, P. and Wiendahl, H.-P., 2003. Logistische Kennlinien: Grundlagen, Werkzeuge und Anwendungen, 2nd Edition, Springer-Verlag, Berlin, Heidelberg, New York, 199.

Nyhuis, P. and Vogell, M., 2006. Adaptation of Logistic Operating Curves to onepiece flow processes, Journal of Productivity and Performance, 55, 284-299.

Nyhuis, P., 2007. Practical Applications of Logistic Operating Curves. Annals of the CIRP, 56, 483-486.

Nyhuis, P. and Wiendahl, H.-P., 2008. Fundamentals of Production Logistics: Theory, Tools and Applications, Springer, Berlin, Heidelberg, 59-178.

Papula, L., 1994. Mathematik für Ingenieure und Naturwissenschafttler, ViewegVerlag, Braunschweig, Wiesbaden.

Pollett P. K., 2000. Modelling congestion in closed queuing networks, International Transactions in Operations Research, 7, 319-330.

Roser C., M. and Nakano, 2003. Comparison of bottleneck detectioni methods for AGV systems. 2003 Winter Simulation Conference, 1192-1198.

Stephen, R. and Arnold H., 1995. Economic analysis of production bottlenecks, Mathematical Problems in Engineering, 1, 341-363.

Schneider, M., 2004. Logistische Fertigungsbereichskennlinien, Fortschritt-Berichte, VDI, Düsseldorf.

Scholz-Reiter, B.; Windt, K. and Liu, H, 2009. A preliminary investigation on a bottleneck concept in manufacturing control, 2nd International Conference on Dynamics in Logistics, Springer-Verlag, Bremen, Germany.

Windt, K., 2001. Engpaßorientierte Fremdvergabe in Produktionsnetzwerken, Fortschritt-Berichte VDI, Düsseldorf, 59-65.

Wiendahl, H.-P. and Nyhuis,P., 1993. Die logistische Betribskennlinie-ein neuer Ansatz zur Beherrschung der Productionslogistik, In RKW(Eds.):RKWHandbuch Logistik, Erich Schmidt Verlag, Berlin.

Wiendahl, H.-P., 1995. Load-Oriented Manufacturing Control, Hanover, SpringerVerlag.

Wiendahl, H.-P. and Möller,J, 1995. Engpaßorienttierte Logistikanalyse auf der Basis von Betriebskennlien, Io Management Zeitschrift 64, 27-33.

Wiendahl, H.-P. and Nyhuis,P., 1998, Engpaßorienttierte Logistikanalyse-Mothoden zur kurzfristigen Leistungsteigerung in Productionsprozessen, Munich, Transfer Centrum GmbH.

Wang, Y., Zhao, Q. and Zheng, D., 2005. Bottlenecks in production networks: an overview. Journal of Systems Science and Systems Engineering, 14, 347-363.

Yu, K.-W., 2001. Terminkennlinie - Eine Beschreibungsmethodik für die Terminabweichung im Produktionsprozess, Fortschritt-Berichte VDI, Düsseldorf, 71 . 
Yan HS, An YW and Shi WW. , 2009. A new bottleneck detecting approach to productivity improvement of knowledgeable manufacturing system, Journal of Intelligent Manufacturing, Doi:10.1007/s10845-009-0244-3

Yan H.S., 2006. A new complicated-knowledge representation approach based on knowledge meshes. IEEE Transactions on Knowledge and Data Engineering $18,47-62$.

Zäpfel, G. and Piekarz, B., 1998. Regelkreisbasiertes Supply Chain Controlling, in: Wildemann, H. (Hrsg.): Innovationen in der Produktionswirtschaft: Produkte, Prozesse, Planung und Steuerung, TCW Transfer-Centrum-Verlag, München, 63-65. 


\begin{tabular}{|c|c|l|l|}
\hline $\begin{array}{c}\text { Work - } \\
\text { station } \\
\text { No. }\end{array}$ & $\begin{array}{c}\text { Production } \\
\text { Segment } \\
\text { No. }\end{array}$ & \multicolumn{1}{|c|}{ Description } & \multicolumn{1}{|c|}{$\begin{array}{c}\text { Shift } \\
\text { calendar } \\
\text { No. }\end{array}$} \\
\hline 37701 & 77 & Drilling_1 & FS7860 \\
\hline 37702 & 77 & Drilling_2 & FS7860 \\
\hline 37703 & 77 & Drilling_3 & FS7860 \\
\hline 37704 & 77 & Drilling_4 & FS7860 \\
\hline 37801 & 78 & Manual turning_1 & FR39 \\
\hline 37802 & 78 & Manual turning_2 & FR39 \\
\hline 37803 & 78 & Manual turning_3 & FR39 \\
\hline 37804 & 78 & Manual turning_4 & FR39 \\
\hline 37901 & 79 & CNC turning_1 & FS7812 \\
\hline 37902 & 79 & CNC turning_2 & FS7812 \\
\hline 37903 & 79 & CNC turning_3 & FS7812 \\
\hline 37904 & 79 & CNC turning_4 & FS7812 \\
\hline 37905 & 79 & CNC turning_5 & FS7812 \\
\hline 38101 & 81 & CNC center_1 & FS7861 \\
\hline 38102 & 81 & CNC center_2 & FS7861 \\
\hline 38104 & 81 & CNC center_3 & FS7861 \\
\hline 38105 & 81 & CNC center_4 & FS7861 \\
\hline 38106 & 81 & CNC center_5 & FS7861 \\
\hline 38107 & 81 & CNC center_6 & FS7861 \\
\hline 38108 & 81 & CNC center_7 & FS7861 \\
\hline
\end{tabular}

Table 1.Production facilities in the production network

\begin{tabular}{|c|c|c|c|c|}
\hline $\begin{array}{c}\text { Work - } \\
\text { station } \\
\text { No. }\end{array}$ & $\begin{array}{c}\text { Sum of } \\
\text { throughput } \\
\text { times [Hrs] }\end{array}$ & $\begin{array}{c}\text { Relative } \\
\text { proportion of } \\
\text { throughput } \\
\text { time [\%] } \\
\end{array}$ & $\begin{array}{c}\text { Production } \\
\text { Segment } \\
\text { No. }\end{array}$ & $\begin{array}{c}\text { Relative } \\
\text { proportion of } \\
\text { throughput } \\
\text { time [\%] }\end{array}$ \\
\hline 37701 & 6120.1347 & 15.7748 & \multirow{4}{*}{77} & \multirow{4}{*}{14.1552} \\
\hline 37702 & 5199.9653 & 13.4030 & & \\
\hline 37703 & 4820.7078 & 12.4255 & & \\
\hline 37704 & 5826.2933 & 15.0174 & & \\
\hline 37801 & 1277.5922 & 3.2930 & \multirow{4}{*}{78} & \multirow{4}{*}{3.3212} \\
\hline 37802 & 1200.9428 & 3.0955 & & \\
\hline 37803 & 1330.5572 & 3.4295 & & \\
\hline 37804 & 1344.9533 & 3.4667 & & \\
\hline 37901 & 1410.2969 & 3.6351 & \multirow{5}{*}{79} & \multirow{5}{*}{3.6503} \\
\hline 37902 & 1478.2722 & 3.8103 & & \\
\hline 37903 & 1445.1261 & 3.7248 & & \\
\hline 37904 & 1538.3536 & 3.9651 & & \\
\hline 37905 & 1209.1364 & 3.1166 & & \\
\hline 38101 & 577.7297 & 1.4891 & \multirow{7}{*}{81} & \multirow{7}{*}{1.6918} \\
\hline 38102 & 694.9919 & 1.7914 & & \\
\hline 38104 & 665.9847 & 1.7166 & & \\
\hline 38105 & 611.0317 & 1.5749 & & \\
\hline 38106 & 665.2703 & 1.7148 & & \\
\hline 38107 & 576.2503 & 1.4853 & & \\
\hline 38108 & 803.3061 & 2.0705 & & \\
\hline
\end{tabular}

Table 2.Static throughput time bottlenecks 


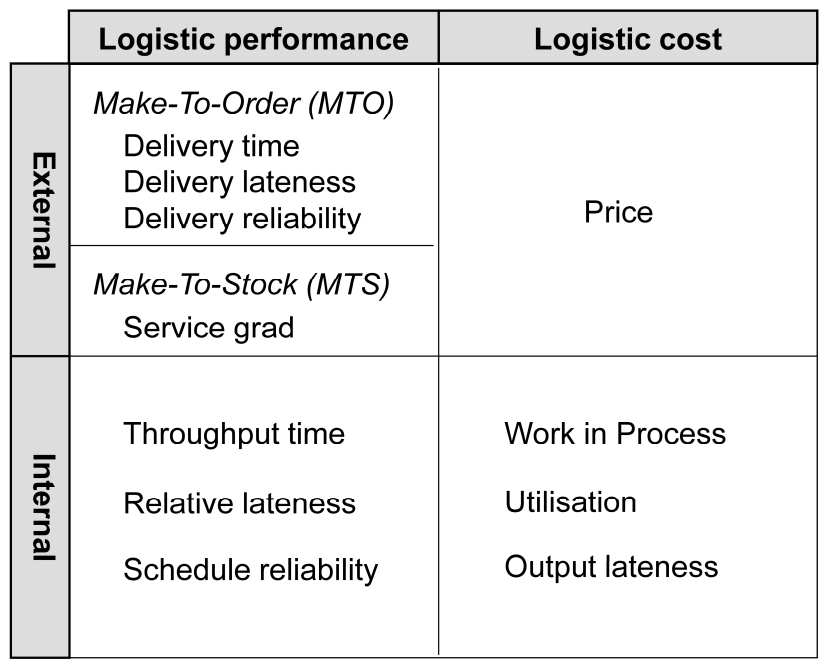

Figure 1.Logistic objectives (Lödding, 2005)

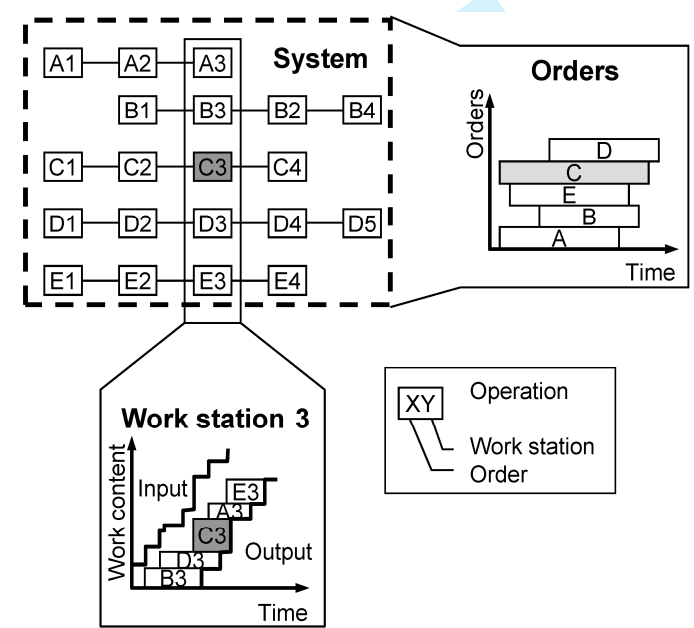

Figure 2.Order throughput time and workstation throughput time

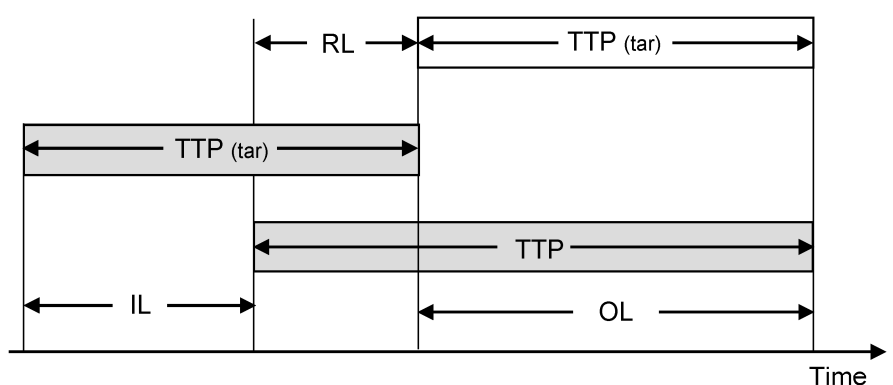

IL : Input lateness [hrs] OL : Output lateness [hrs]

$\mathrm{TTP}_{\mathrm{i}}$ : Actual throughput time [hrs] $\mathrm{TTP}_{(\mathrm{tar})}$ : Target throughput time [hrs]

$\mathrm{RL}_{\mathrm{i}}=\mathrm{TTP}_{\mathrm{i}}-\mathrm{TTP}_{\mathrm{i},(\mathrm{tar})}$ : Relative lateness [hrs]

Figure 3.Relative lateness for an operation (Nyhuis, 2003) 


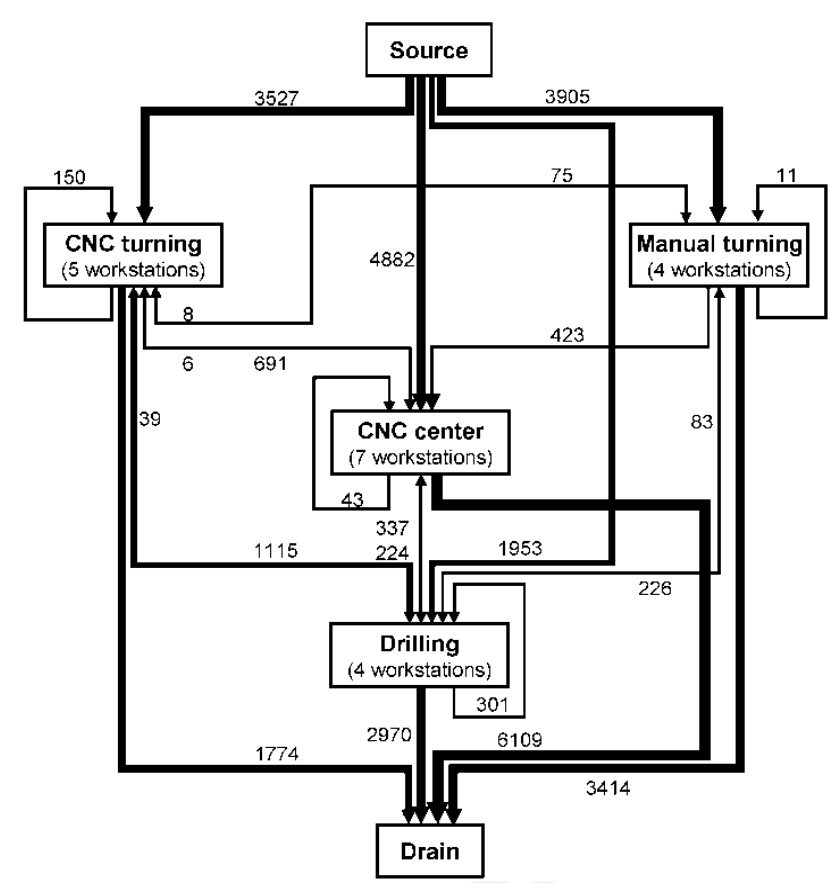

Figure 4.Material flows in the analysed production network
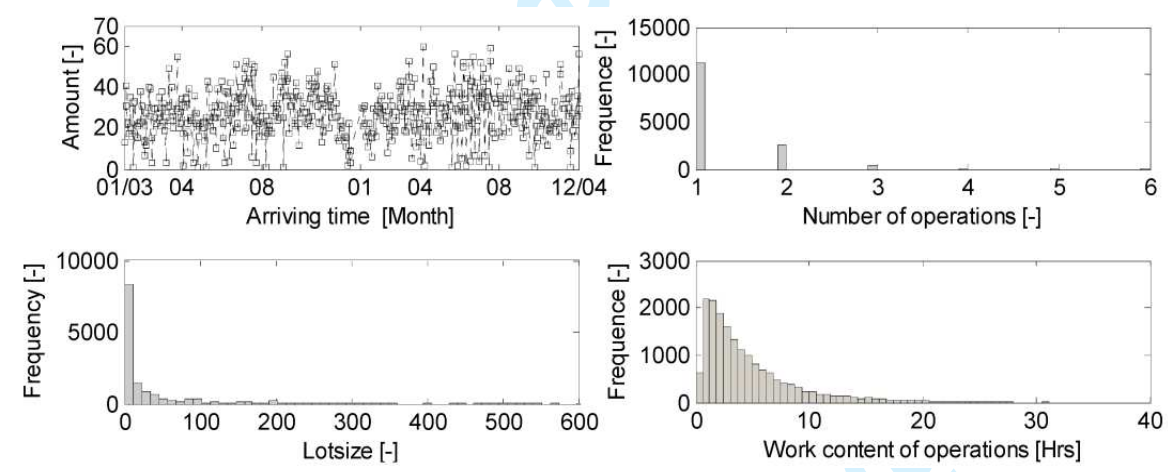

Figure 5.Diverse characteristics of incoming production orders
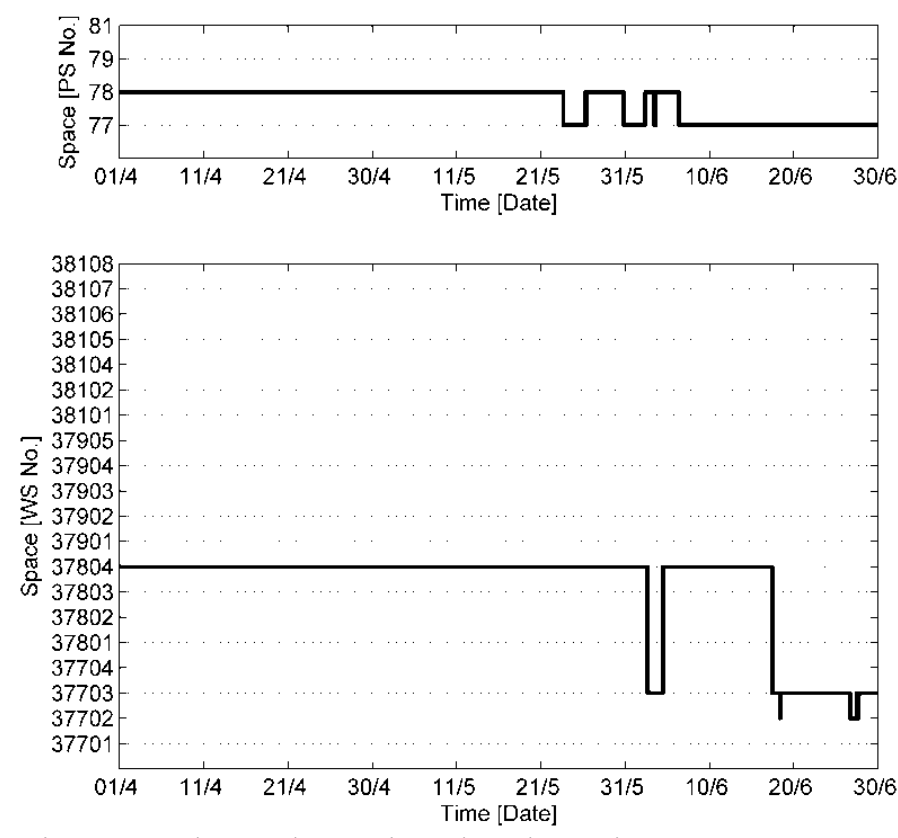

Figure 6.Throughput time bottlenecks 

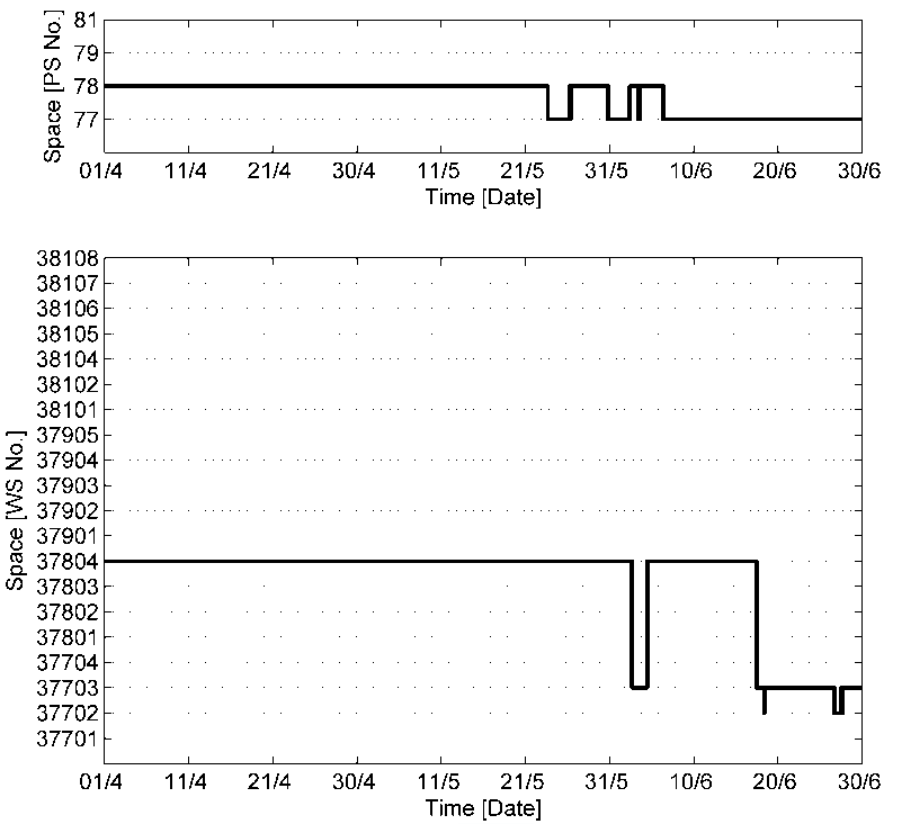

Figure 7.Relative lateness bottlenecks
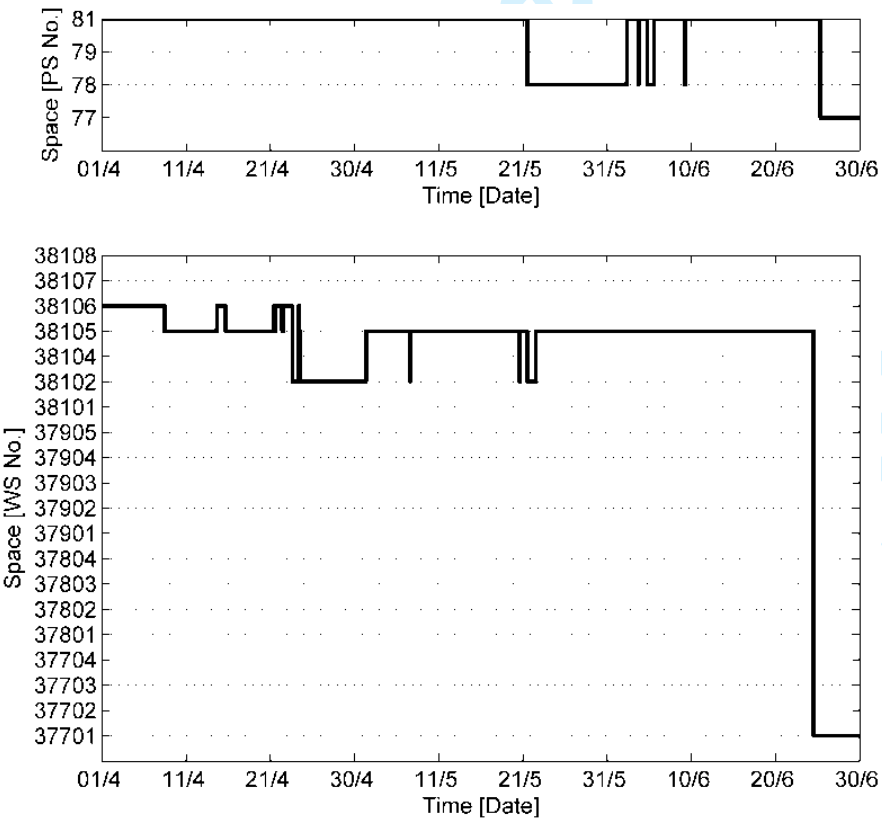

Figure 8.Schedule reliability bottlenecks 

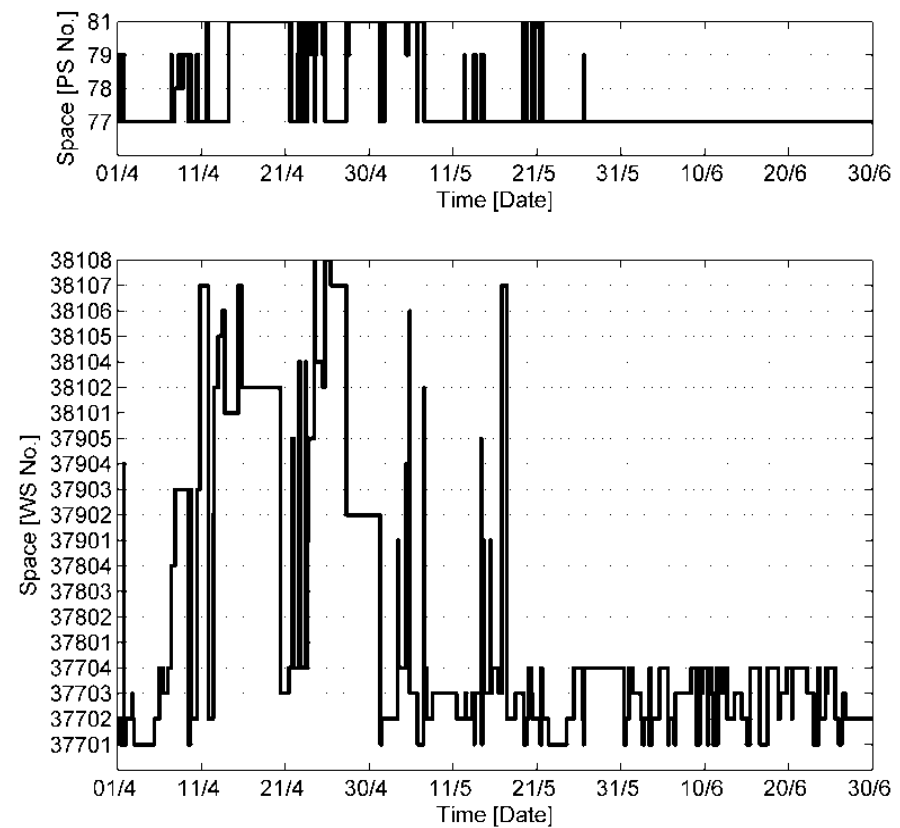

Figure 9.Work in Process and throughput bottlenecks
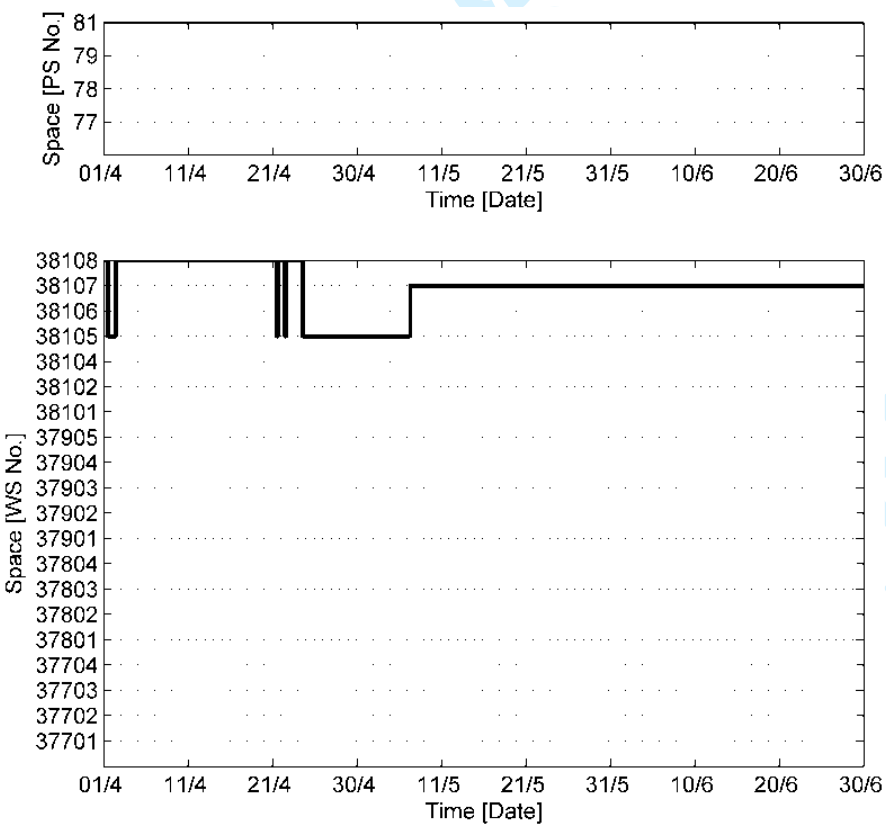

Figure 10.Utilization loss bottlenecks 


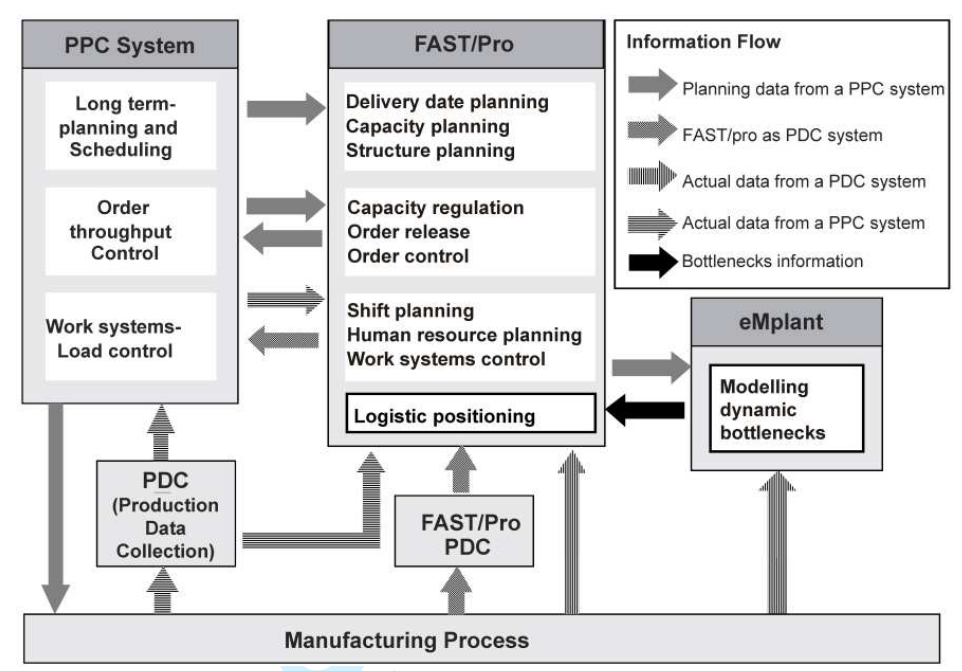

Figure 11.Practical application of modelling dynamic bottlenecks

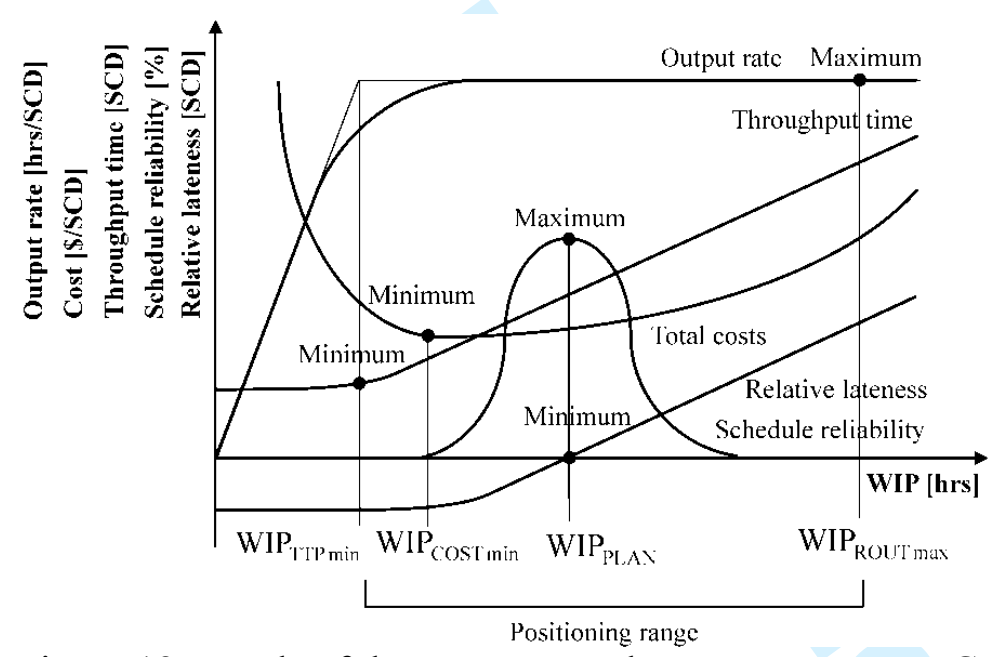

Figure 12.Trends of the WIP Dependent TTP, RL, Res, Costs and Output Rate (Nyhuis and Wiendahl 2008)

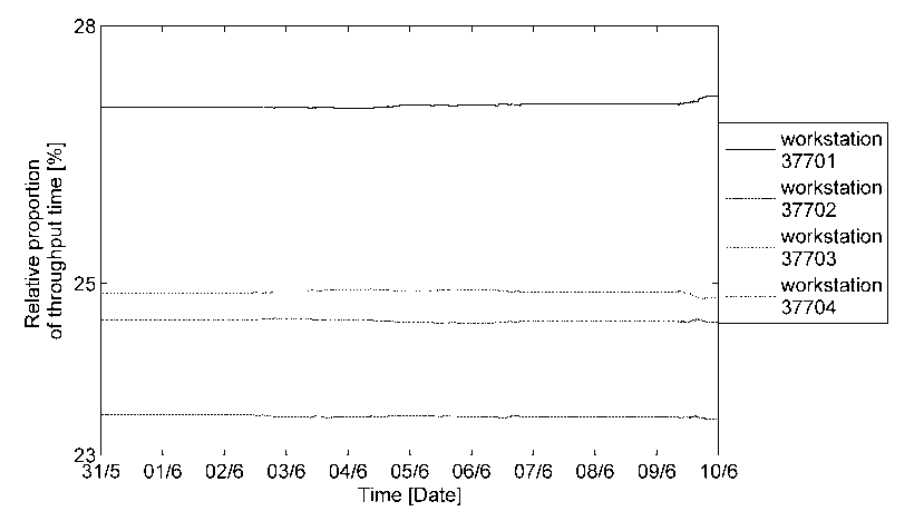

Figure 13.WIP trend of bottleneck production segment's bottleneck workstation 